\title{
ANTARA INDIVIDUALITAS DAN KOLEKTIVITAS: STUDI HUBUNGAN PEMAIN GIM PLAYERUNKNOWN'S BATTLEGROUNDS (PUBG) MOBILE
}

\author{
Muhammad Guntur Cobobi \\ Pascasarjana Antropologi, Fakultas Ilmu Sosial dan Ilmu Politik, Universitas Indonesia \\ e-mail:gunturcoboby@ymail.com
}

\begin{abstract}
Abstrak
Selama ini para ilmuwan sosial berdebat tentang bagaimana tindakan individual dan kolektif pada interaksi manusia. Asumsi yang cenderung dipakai dalam perdebatan tersebut adalah antara individualitas dan kolektivitas sebenarnya tidak berdiri sendiri, sebab keduanya saling mempengaruhi, bahwa suatu tindakan kolektif sesungguhnya dibangun dari individu-individu yang bekerjasama secara kolektif. Asumsi-asumsi ini berangkat dari studi terhadap masyarakat yang memiliki keterikatan struktural dengan intensionalitas interaksi yang tinggi. Lantas bagaimana jika fenomena empiriknya digeser pada masyarakat egaliter yang tidak terikat struktur di dunia virtual? Kajian pada studistudi tentang interaksi pemain gim daring dan metode etnografi virtual pada dialektika yang terjadi dalam interaksi antara pemain gim Playerunknown's Battlegrounds (PUBG) Mobile, menunjukkan bahwa terdapat kecenderungan yang dapat mengubah asumsiasumsi terdahulu mengenai individualitas dan kolektivitas dikarenakan oleh kompleksitas interaksi yang terbangun dalam ruang tersebut.
\end{abstract}

Kata kunci: Individualitas, Kolektivitas, Pemain Gim, PUBG Mobile

The Correlation Between Individuality and Collectivity: Study of the Relationship Between PlayerUnknown's Battlegrounds (PUBG) Mobile Game Player

Abstract

During this time, social scientists debate about how individual and collective action on human interaction. The assumption which tends to be used in the debate is between individuality and collectivity does not stand by themselves, because both affect each other, that collective action is actually built from individuals who collaborate collectively. These assumptions come from studies of societies which have structural engagements with high intentionality of interaction. So what if the empirical phenomenon is shifted to an egalitarian society that is not bound by structure in the virtual world? Analysis on studies of online game player interactions and virtual ethnographic methods in that dialectics which occur interactions between Game Player Player's Mobile Battlegrounds (PUBG) show which there is a tendency to change previous assumptions about individuality and collectivity due to complex interactions that develop in that space.

Keywords: individuality, collectivity, game player, PUBG Mobile 


\section{Pendahuluan}

Manusia adalah makhluk sosial, karena itu antar sesamanya saling membutuhkan satu sama lain. Sebagai perwujudannya, maka mereka saling berinteraksi. Walgito (2007) mengatakan bahwa interaksi sosial adalah suatu hubungan antara individu yang satu dengan individu yang lain maupun individu dengan kelompoknya, ketika proses ini terjadi, terciptalah hubungan timbal-balik yang saling mempengaruhi satu dengan yang lain. Dalam interaksi antarindividu atau individu dengan kelompok senantiasa terdapat ketegangan yang berdialektika, ketegangan-ketegangan tersebut dapat berupa kompetisi, konflik, kontravensi, dan akomodasi (Sarwono dan Meinarno, 2009). Prayitno (2006) berpendapat bahwa pada dasarnya, dalam keindividualan senantiasa terdapat dimensi kesosialan, artinya individu membutuhkan kelompok, dinamika ini adalah pengejewantahan dari dialektika individual dan kolektif.

Menurut Bevir (1996) tindakan-tindakan yang terbangun dalam interaksi antara individu dengan komunitasnya pada dasarnya dibangun oleh suatu sistem yang saling berketergantungan. Ketergantungan menurut Bevir dapat diartikan sebagai pola mutualistik,ini merupakan titik berangkat dari segala perdebatan mengenai dinamika interaksi individualitas dan kolektivitas, sebab bagaimanapun tindakan seseorang tidak terlepas dari apa yang dibentuk oleh komunitasnya, sedangkan sebuah tindakan kolektif juga dibentuk oleh individu-individu di dalam komunitas tersebut.

Berseberangan dengan Bevir, Chakrabarti (1995) melihat bahwa dalam aspek mental dan emosional pada interaksi individu dan kolektif, justru individu lah yang paling sering muncul untuk kemudian dalam skala yang lebih besar dan masif direpresentasikan sebagai sesuatu yang kolektif. Boissevain (1968) juga berasumsi bahwa yang paling mendasar antara individualitas dan kolektivitas adalah individu itu sendiri, menurut Boissevain, segala sesuatu yang berkaitan dengan dinamika sosial harus diurutkan secara logis dari individu itu sendiri. Baginya, dalam perilaku sosial, variabel utama bukan bergantung pada kelompok. Meski demikian, Boissevain tidak lantas menempatkan individu di atas kolektif, sebagaimana Bevir, Boissevain berpendapat bahwa individualitas dan kolektivitas saling mempengaruhi satu sama lain. 
Penelitian-penelitian terdahulu yang mengkaji tentang individualitas dan kolektivitas atau bagaimana individu di dalam kelompoknya seperti yang telah dipaparkan di atas masih mengambil studi pada kelompok masyarakat yang terikat secara struktur, di mana kolektivitas yang terbangun bisa saja didorong oleh keharusan moral yang justru dibangun dari dan secara kelompok. Lalu bagaimana dengan kelompok masyarakat yang tidak terstruktur dan tidak terdefinisi seperti di dunia virtual atau ruang di mana manusia dapat berinteraksi tanpa bertemu secara fisik, tidak diikat oleh standar moralitas tertentu? Penelitian ini mencoba menjawab pertanyaan tersebut dengan mengambil studi empirik pada dinamika interaksi pemain gim PlayerUnknown's Battlegrounds (PUBG) Mobile, sebuah platform gim bergenre Battle Royale yang saat ini sedang populer.

Mengapa penulis memilih gim daring PlayerUnknown's Battlegrounds (PUBG) Mobile sebagai studi empirik dalam menguji konsep individualitas dan kolektivitas? Karena selain gim PUBG Mobile adalah satu di antara sekian banyak sarana interaksi virtual, juga menyediakan fitur-fitur yang memungkinkan pemain gim ini untuk saling bekerjasama dalam sebuah tindakan kolektif dan di saat yang sama bisa mengambil opsi untuk bermain secara individual. Adanya reward atau insentif baik berupa peningkatan level ataupun item-item kepada masing-masing pemain gim juga dapat menjadi petunjuk untuk menganalisis apakah dalam suatu tindakan kolektif terdapat dialektika yang sebenarnya berangkat dari sebuah tindakan individual.

Selama ini, kajian tentang individualitas yang berkaitan dengan pemain gim cenderung melihat individualitas sebagai masalah mental, hal ini terlebih pada disiplin psikologi, kesimpulan yang sering muncul senantiasa mengkonfirmasi pandangan umum yang mengasumsikan bahwa pemain gim anti sosial dan individualistis. Perkembangan gim daring (online) justru telah mematahkan asumsi umum tersebut, sebab dengan fitur-fitur interaksi yang dihadirkan di dalam gim daring justru telah menghadirkan unsur sosialitas ketika seseorang bermain gim, selain itu bentuk interaksi di dalam gim daring juga sangat kompleks (Kusumawardhani, 2015; Husain dan Griffiths, 2009; Lu Jia dkk, 2015). Namun, benarkah jika sosialitas atau tindakan-tindakan kolektif di dalam gim daring dibentuk oleh platform yang justru menegaskan individualitas ataukah justru 
sebaliknya? Pertanyaan ini juga dapat dijawab jika kita mengkaji bentuk-bentuk dari tindakan individual dan kolektif ketika seseorang bermain gim PlayerUnknown's Battlegrounds (PUBG) Mobile.

Tujuan dari penelitian ini adalah melihat lebih jauh kompleksitas interaksi manusia di era virtual dengan cara menguji konsep tentang individualitas dan kolektivitas, yang mana jauh sebelumnya dibangun oleh studi-studi terhadap masyarakat yang memiliki keterikatan struktural dan diakomodir oleh ruang yang masing-masing dipertemukan secara fisik. Dengan menggunakan gim PlayerUnknown's Battlegrounds (PUBG) Mobile sebagai studi kasus, di mana di dalam gim ini terdapat begitu banyak fenomena yang berimplikasi pada tindakan individual dan kolektif, penulis berharap agar nantinya perdebatan akademis di ranah antropologi tentang konsep ini dapat diperkaya dengan fakta empirik terbaru yang secara substantif menjadi masukkan bagi asumsi-asumsi terdahulu.

Adapun konsep-konsep dari penelitian ini diharapkan dapat bermanfaat bagi upaya untuk memahami bahwa dalam interaksi manusia, pada titik tertentu terdapat suatu kerjasama dengan semangat dan proses kolektif, tetapi di saat yang sama bisa saja terbangun oleh tujuan-tujuan individu yang dalam konteks gim PlayerUnknown's Battlegrounds (PUBG) Mobile direpresentasikan dengan keinginan individu untuk menjadi pemenang dengan reward paling maksimal atau menjadi yang paling menonjol di antara yang lain. Dalam disiplin Game Studies, penelitian ini juga bermanfaat bagi pengembangan gim-gim dengan genre serupa yang diharapkan dalam pengembangannya kedepan menghadirkan bentuk-bentuk interaksi yang mempertimbangkan aspek-aspek dan nilai sosial tertentu.

\section{Metode Penelitian}

Metode yang digunakan dalam penelitian ini adalah metode etnografi virtual serta dengan melakukan penelaahan yang mendalam terhadap literatur yang relevan secara teoritik dan fenomelogis melalui buku, artikel, media massa dan lain sebagainya (Nazir, 1988). Dalam hal ini, penulis berfokus pada kajian-kajian tentang individualitas dan kolektivitas, serta studi tentang hubungan antar pemain gim daring. Metode etnografi virtual untuk menggali data yang berkaitan dengan interaksi pemain gim PlayerUnknown's Battlegrounds (PUBG) Mobile digunakan 
untuk menempatkan peneliti sebagai pengamat partisipan yang akan melakukan immersion atau menempatkan diri di dalam arena penelitian bersama dengan subjek yang diteliti (Bate, 1997). Melalui immersion, penulis bisa mengamati, mempelajari, merasakan dan menjalankan perilaku serta kultur para pemain (Sapach, 2015). Penelitian ini menjadikan ruang virtual sebagai arena penelitian, menurut Hine (2000) ini adalah metode penelitian di mana peneliti berupaya untuk memahami kultur yang terjadi di ruang dalam jaringan (daring).

\section{Konsep Individualitas Dan Kolektivitas}

Sudah sejak lama para ilmuwan sosial berupaya membuat batasan antara individualitas dan kolektivitas, sebelum Boissevain (1968) yang pada akhirnya mengajukan bahwa antara individualitas dan kolektivitas adalah sebuah kontinum, Thomas Hobbes dalam Postmes dan Jeten (2006) mengatakan bahwa hubungan antara individu dan kolektif pada dasarnya adalah konflik. Terlepas dari itu, pandangan yang bermunculan terkait dengan kedua konsep ini sangat beragam, ada yang menempatkan individualitas yang berlaku secara kolektif lah yang membentuk kolektivitas itu sendiri (Tajfel, 1978; Baumeister, 1991; Putnam, 2002). Ada pula yang berpendapat sebaliknya, jika kelompok dalam sebuah tindakan dan norma-norma kolektif lah yang membentuk individu untuk bertindak secara kolektif, dalam artian bahwa peran individu menjadi cenderung dikesampingkan (Janis, 1982; Hogg \& Abrams, 1990; Turner, 1999).

Individualitas berakar dari kata 'individu' atau 'in-dividere' yang merupakan kata dalam bahasa Perancis (Gerungan, 2004), pengertiannya merujuk pada satu orang yang juga berfungsi sebagai pembeda dengan masyarakat atau kelompok. Menurut Newcomb (1968) individu dalam suatu masyarakat adalah sebuah proses saling membangun dan menempatkan diri, baik secara pribadi maupun kelompok, di mana selalu ada kecenderungan individu satu sama lain berusaha menempatkan dirinya dalam akumulasi kebiasaan yang tercipta secara kelompok, yang dalam hal ini terbentuk oleh himpunan individu-individu, sehingga bagaimanapun, keberadaan individu tidak bisa terlepas dari kelompok atau masyarakat itu sendiri. 
Lebih lanjut, Rorty dalam Ramberg (2014) membuat batasan individu sebagai apa yang bersifat singular, partikular, privat dan independent, tidak memiliki keterikatan apapun dengan kelompok atau sesuatu diluar singularitas itu, tetapi memungkinkan terjadinya relasi dengan yang lain dalam bentuk noninterdependensi. Di sini, Rorty menekankan kontradiksi antara individu dan sosial, menurutnya jika individu melebur dalam kehidupan sosial, maka individu tersebut akan kehilangan identitas individu itu sendiri. Luhmann dalam Lee (2000) memiliki pandangan yang bertolakbelakang dengan Rorty, dengan menggunakan paradigma konfusian, menurutnya individu tidak terbatas pada singularitas atau partikularitas yang sepenuhnya berkontradiksi dengan apapun yang bersifat sosial atau kelompok, sebab individu itu adalah bentuk utuh dari lingkungan sosial itu sendiri.

Secara operasional, konsep individualitas yang dimaksud dalam studi ini adalah sebuah tindakan yang berorientasi pada motif pribadi, sebagaimana batasan Turner dkk (1994) yang mengatakan bahwa individualitas adalah produk dari identitas pribadi dan hanya mewakili tingkat perilaku dengan satu skala identitas di dalam sebuah kelompok. Ini tentu saja berbeda dengan individualisme yang merupakan suatu paradigma filsafat yang berorientasi pada pandangan moralitas dan politik tentang kemerdekaan manusia yang berasas pada kebebasan diri sendiri tanpa terikat oleh subjek-subjek yang lain (Franck, 2000). Lebih lanjut, individualitas adalah ketika seseorang selain berperilaku, juga berpikir, merasakan dan memahami sesuatu secara berbeda dengan anggota kelompok lainnya. Sejalan dengan Turner, Hogg (2008) berpandangan bahwa individualitas adalah bagaimana seorang individu bertindak dan menempatkan dirinya dalam kelompoknya.

Tindakan individual juga dapat dikaitkan dengan ego pribadi, Kesselring dan Muller (2011) mengatakan bahwa sebuah tindakan individu yang berasal dari interpretasi jika dirinya adalah pusat dari lingkungannya dan dengan demikian menempatkan semuanya pada kebutuhan pribadi adalah suatu bentuk egosentrisme (egocentrism). Egosentrisme memiliki ciri-ciri seperti; mementingkan diri sendiri, minim kepedulian kepada yang lain, kurang peka terhadap ruang sosial, serta merasa dirinya merupakan sentral dari sebuah dinamika di mana ia ada di dalamnya. Dapat dipastikan, egosentrisme tidak memiliki tempat dalam proses sosial yang 
berbasis pada suatu kerangka kolektif, sebab selalu ada kecenderungan yang melemahkan kolektivitas tersebut.

Sedangkan kolektivitas dalam konteks ini dapat didefinisikan sebaliknya, yakni jamak, tidak tunggal, kelompok dan banyak. Secara umum kolektivitas adalah keadaan yang dibangun dalam nuansa pro sosial. Gittel dan Vidal (1988) mengatakan bahwa kolektivitas adalah kecenderungan kekuatan relatif yang secara serentak terbangun dari ikatan yang menghubungkan individu-individu di dalam suatu kelompok. Gittel dan Vidal melihat bahwa dalam masyarakat yang terikat secara spasial, juga memiliki keterikatan moral untuk tidak hanya berada dalam satu ruang yang sama, namun juga pada tindakan-tindakan dengan tujuan yang sama.

Pandangan Gittel dan Vidal berangkat dari gagasan tentang integrasi masyarakat yang diajukan oleh Durkheim, di mana dalam argumentasinya mengatakan bahwa masyarakat modern yang hidup dalam sebuah siklus yang diisi dengan pembagian-pembagian kerja, sebab pada dasarnya manusia hidup saling bergantung satu sama lain, sederhananya menurut Durkheim kolektivitas atau tindakan sosial cenderung dibangun dan diarahkan oleh norma-norma dan solidaritas kelompok tempat di mana individu tersebut tinggal (Rudyansjah, 2015). Sependapat dengan Gittel dan Vidal, Hatfield dkk (2014) mengatakan jika kolektivitas adalah suatu perasaan bersama yang terbangun dari individu-individu yang ada dalam suatu kelompok.

Kolektivitas sebagai sebuah tindakan sosial pada dasarnya mengacu pada definisi yang dikemukakan oleh Max Weber, seperti dikutip oleh Ritzer (1990) bahwa suatu tindakan dapat dikatakan sebagai sebuah tindakan sosial apabila tindakan tersebut berhubungan, mempengaruhi atau dipengaruhi oleh orang lain bahkan jika itu tidak diungkapkan dalam tindakan fisik sekalipun, menurut Weber, jika berkaitan atau diarahkan untuk orang lain maka itu dapat dikategorikan sebagai sebuah tindakan sosial. Namun demikian, terdapat anomali dalam pandangan Weber terkait dengan subjektivitas dalam sebuah tindakan sosial, di mana kolektivitas di sini adalah resultan dari sebuah tindakan individu, sehingga pandangan Weber hampir seluruhnya berkutat pada invidualitas, bukan kolektivitas. 
Sementara itu, Karl Marx dalam Sayers (2007) melihat bahwa kolektivitas yang terbangun dalam sebuah tindakan sosial adalah bentuk aktivitas manusia yang bekerja dalam unit-unit tertentu di dalam kelompok untuk masing-masing mengejar tujuan-tujuan tertentu sebenarnya bersifat individual, sehingga menurut Sayer, pandangan kolektivitas Marx adalah individualitas yang terkolektifkan. Sejalan dengan Marx, Talcott Parsons dalam bukunya the structure of social action sebagaimana dikutip King (2009) mengatakan bahwa kolektivitas dalam sebuah tindakan sosial berorientasi pada satu tujuan yang sama, dalam hal ini Parsons menurut King melihat bahwa orientasi tujuan sebagai ketercapaian individu bisa jadi adalah kolektivitas jika berlangsung secara kelompok.

Perdebatan para ilmuwan sosial mengenai tindakan individu dan kolektif, umumnya bermuara pada dua kesimpulan yang saling berhadap-hadapan, kesimpulan pertama mengatakan jika tindakan individu terpisah secara total dari kelompok sedangkan kesimpulan kedua mengatakan bahwa tindakan individu tidak bisa dipisahkan dari kelompok itu sendiri. Beberapa ilmuwan sosial berupaya menggunakan kesimpulan kedua sebagai jembatan bagi perdebatan panjang antara individualitas dan kolektivitas. Gluckman (2017) menggunakan analogi proton, elektron dan neutron di dalam inti atom, menjelaskan bahwa individu dan kolektif saling mempengaruhi dan dipengaruhi. Sepemikiran dengan Gluckman, Turner dkk (2006) menyebut bahwa individualitas dan kolektivitas saling terikat dan berketergantungan satu sama lain, kelompok pada dasarnya dibentuk dan dipimpin oleh individu dan diisi dengan tindakan-tindakan individual yang mensubordinasikan dirinya secara kolektif dalam kelompok, sedangkan individu yang berada di dalamnya dibentuk dan ditransmisikan kekuatannya untuk terus hidup oleh kelompok.

Berangkat dari beragam pandangan para ilmuwan sosial, asumsi tentang individualitas dan kolektivitas sesungguhnya bisa terisolir, selain pada ruang juga pada waktu, sebagaimana pandangan Niklas Luhmann bahwa pada masyarakat tradisional, individu cenderung bersifat inklusif, di mana ia merupakan bagian dari kelompok untuk saling melengkapi dan mempengaruhi satu sama lain. Sedangkan pada masyarakat modern, individu senantiasa bersifat eksklusif dan mengagregasi dirinya dengan apapun yang bersifat kelompok, fakta ini dipengaruhi oleh 
kompleksitas di dalam masyarakat modern itu sendiri, sehingga meskipun sistem dan struktur yang diisi dengan norma-norma masih tetap ada, tetapi individu cenderung bertindak berbeda dari ketentuan moral dan norma kelompoknya.

Pada perkembangannya, kecenderungan bertindak individual menjadi dinamika kontemporer, menurut Nassehi (2002) manusia senantiasa menanggalkan perasaan kolektif untuk mengejar tujuan individu, meskipun sistem masyarakat modern dibangun dengan landasan kolektif namun pada prosesnya tidak diimbangi dengan semangat kolektif dari setiap individunya, kompleksitas seperti ini menarik untuk dikaji dalam rangka memproblematisasikan kembali bagaimana individualitas dan kolektivitas di masyarakat modern yang juga terkoneksi di ranah virtual.

\section{Gim PlayerUnknown's Battlegrounds (PUBG) Mobile}

PlayerUnknown's Battlegrounds (PUBG) Mobile atau yang lebih dikenal dengan sebutan PUBG Mobile adalah gim yang bergenre Battle Royale yang dikembangkan oleh kolaborasi pengembang gim daring terkemuka seperti PUBG Corporation, Tencent Games dan Lighspeed \& Quantum Studios. Gim ini telah dimainkan oleh lebih dari 100 juta orang di seluruh dunia hanya pada perangkat seluler saja, di mana Indonesia berada di urutan kedua terbanyak yang memainkan game ini ${ }^{1}$. Secara keseluruhan, termasuk konsol dan komputer, game ini bahkan telah memiliki lebih dari 400 juta pemain di seluruh dunia ${ }^{2}$, fakta terbaru yang diklaim pengembang jika aplikasi gim daring ini telah diunduh oleh lebih dari 600 juta orang di seluruh dunia. Karena banyaknya fitur di dalam gim, maka gim ini hanya dapat dimainkan pada perangkat berspesifikasi tinggi melalui ponsel pintar maupun perangkat computer, meskipun mahal namun tidak membatasi minat para pemain gim.

Pesatnya perkembangan gim daring seperti PUBG Mobile tidak lepas dari industrialisasi sektor olahraga digital bertajuk e-Sport yang digalakkan secara

\footnotetext{
${ }^{1}$ Baca: https://katadata.co.id/berita/2019/05/25/indonesia-peringkat-kedua-pemain-aktif-pubgterbanyak-di-dunia (diakses pada 10 Desember 2019)

${ }^{2}$ Baca: https://kumparan.com/kumparantech/jumlah-pemain-pubg-capai-400-juta-di-seluruh-dunia (diakses pada 10 Desember 2019)
} 
global (Jonasson dan Thiborg, 2010). Sebagai bagian dari budaya populer, gim daring seperti PUBG Mobile menjadi fenomena yang menarik untuk diteliti, sebab di sana terdapat begitu banyak kebiasaan baru, interaksi yang bebas dan egaliter, kerjasama yang terjalin tanpa harus diikat oleh suatu struktur sosial yang kaku, serta standar-standar moral dan norma tertentu yang muncul dan berkembang dengan sendirinya, tanpa mampu direkayasa bahkan oleh pengembang (developer) gim itu sendiri.

PUBG Mobile adalah gim daring yang memiliki alur permainan di mana sebanyak 100 orang diterjunkan di dalam sebuah lokasi (map) untuk saling membunuh satu sama lain, masing-masing dari mereka kemudian mencari dan mengambil senjata yang digunakan sebagai alat untuk mempertahankan diri, yang paling terakhir tersisa adalah yang keluar sebagai pemenang dalam permainan ini. Para pemenang dalam satu skuad akan mendapatkan rating yang nantinya menjadi indikator dalam meningkatkan level permainan mereka, rating ini juga penting dan memungkinkan mereka untuk mendapatkan reward.

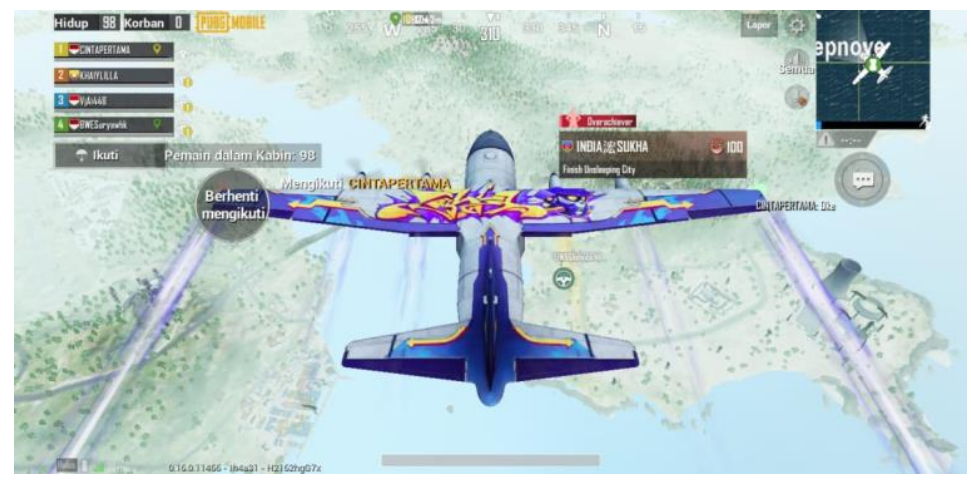

Gambar 1. Tangkapan layar ketika pemain dalam mode squad hendak terjun dalam suatu map untuk memulai permainan (Sumber: dok. pribadi).

Selama 30 menit total waktu bermain, lingkaran zona aman akan terus mengecil dan mengharuskan semua pemain yang terlibat di dalam permainan untuk menuju ke satu lokasi di mana zona aman tersebut berada, sebab jika tidak maka pemain akan terbunuh di luar zona, alur ini pada akhirnya akan mempertemukan pemain-pemain yang tersisa dalam satu lokasi di dalam zona aman untuk kemudian saling membunuh agar menjadi pemenang yang paling terakhir tersisa. 


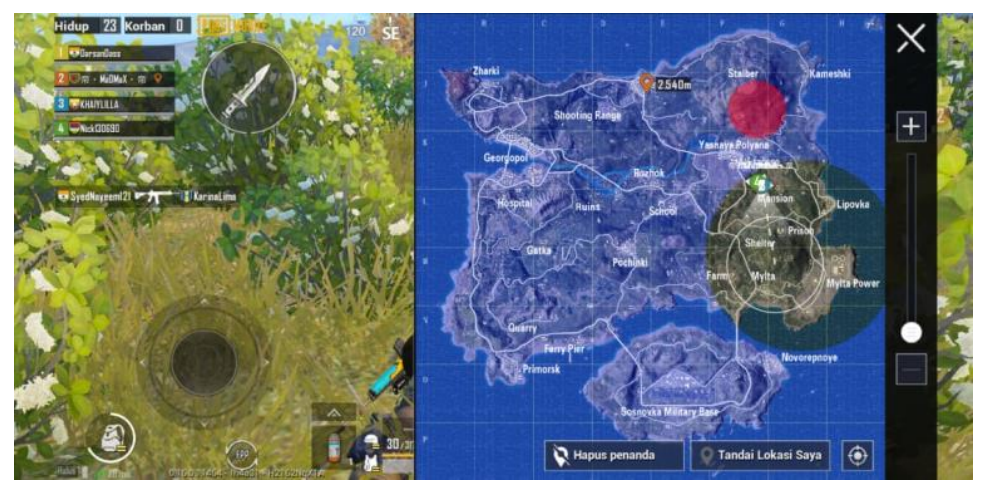

Gambar 2. Tangkapan layar zona aman yang terus bergerak mengecil, pemain yang masih berada di luar zona (area berwarna biru) akan mati perlahan-lahan (Sumber: dok. pribadi).

Dalam mode skuad yang beranggotakan empat orang, pemain diharuskan untuk saling berkoordinasi, membantu dan bekerjasama sebagai tim, termasuk menjalankan strategi-strategi tertentu agar dapat keluar sebagai pemenang, pada mode ini pemain diharuskan untuk bertindak secara kolektif agar tujuan tersebut dapat tercapai. Untuk memudahkan pemain dalam bekerjasama, maka disediakan fitur komunikasi suara dan teks yang memungkinkan sesama pemain dalam satu skuad atau duo untuk saling berkomunikasi, selain antar sesama anggota skuad, pemain juga dimungkinkan untuk berkomunikasi dengan lawannya apabila kedua belah pihak sama-sama mengaktifkan fitur voice dan microfon dalam opsi all.

Selain mode skuad dan mode duo, di mana pemain bermain dalam regu empat atau dua orang, juga terdapat pilihan bermain dalam mode solo, di mana pemain hanya bermain seorang diri. Dalam mode ini, pemain juga akan bermain melawan musuh yang juga memilih mode solo. Alur permainan juga sama dengan mode skuad dan duo, pemain diharuskan untuk saling membunuh satu sama lain, satu pemain terakhir yang masih hidup akan keluar sebagai pemenang permainan. Jika melihat pola bermain, maka mode solo berimplikasi pada kelincahan (skill) pemain, tanpa keharusan bekerjasama, pemain hanya fokus pada permainan yang harus dimenangkan dengan kemampuannya sendiri, sehingga penekanan pada kemampuan individual menjadi sangat dibutuhkan dalam mode ini.

Pemain yang terlibat di dalam permainan akan mendapatan rating sesuai dengan apa yang dicapainya di dalam gim, rating dilihat dari seberapa banyak pemain mendapatkan kill (membunuh musuh), menciptakan damage (mencederai musuh), dan melakukan revive (menyembuhkan teman ketika dilumpuhkan oleh 
musuh). Rating akan diakumulasikan lebih besar apabila skuad atau pemain keluar sebagai pemenang dan diurutkan peringkatnya dari 100 karakter yang terlibat pertempuran di dalam map. Selanjutnya rating ini dapat memungkinkan pemain meningkatkan rank atau pangkat karakternya di dalam permainan, Adapun rank atau pangkat di dalam gim PUBG Mobile dimulai dari yang terendah adalah Bronze, Silver, Gold, Platinum, Diamond, Crown, Ace dan yang tertinggi adalah conqueror.

Sebenarnya ada pangkat paling tinggi dalam gim ini, yakni legendary, namun belum ada pemain yang mampu mencapainya. Untuk naik ke rank berikutnya, pemain harus menyelesaikan rank sebelumnya sebanyak lima tingkatan untuk setiap rank, sehingga semakin tinggi rank pemain maka semakin tinggi pula kemampuan dan intensitasnya bermain gim. Sebaliknya, apabila pemain terbunuh lebih awal, maka rating-nya akan berkurang sehingga secara otomatis mempengaruhi penurunan rank pemain.

Semua pemain yang masuk ke dalam gim akan memulai dari rank terendah di awal season, yaitu ketika item-item dan reward diperbaharui untuk mendongkrak minat pemain agar terus bermain. Item-item terbaru selalu ditawarkan dalam setiap season yang berlangsung kurang lebih tiga bulan sekali. Namun begitu, item-item seperti setelan suit (baju yang dikenakan karakter pemain), skin senjata, maupun kendaraan yang berhasil dikumpulkan pemain di season sebelumnya akan terus ada secara permanen di dalam inventaris pemain yang bisa digunakan kapan saja pemain menginginkannya.

Adapun item-item seperti suit, skin, emoticon, atau desain kendaraan yang digunakan oleh karakter pemain di dalam gim, selain diperoleh melalui reward atau mekanisme royale pass di tiap season, juga melalui kupon peti yang dibeli menggunakan sistem transaksi UC, sebuah mata uang di dalam gim yang dapat dibeli oleh pemain secara digital, namun untuk memperoleh item-item langka, maka pemain hanya dapat mengandalkan keberuntungan atau harus mengeluarkan uang yang sangat besar. Sulitnya mendapatkan item-item tersebut membuat pemain berusaha keras untuk bermain agar memperoleh kesempatan untuk mendapatkanya secara gratis melalui reward. 


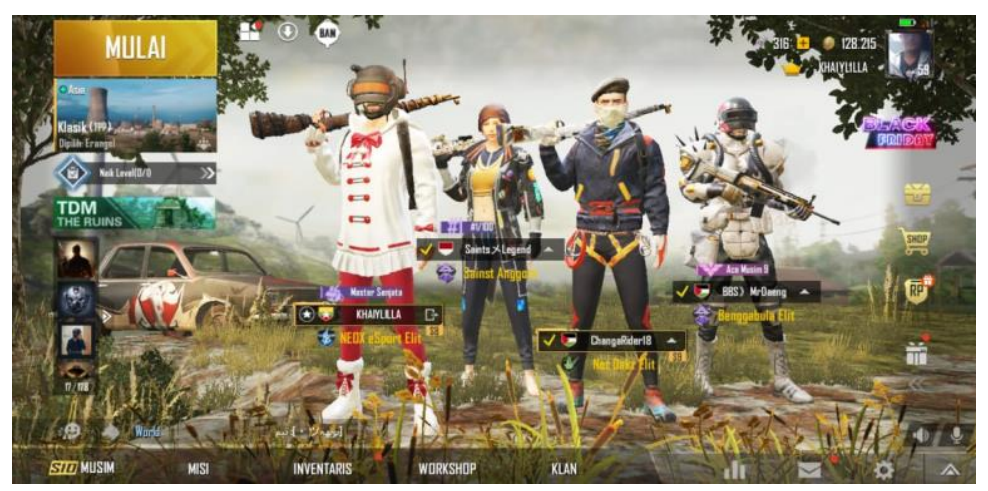

Gambar 3. Tangkapan layar karakter pemain sebelum terjun ke arena pertempuran, masingmasing pemain menata karakternya dengan item suit dan skin yang berhasil didapatkannya (Sumber: dok. pribadi).

Sama seperti gim daring lainnya atau dengan genre serupa, reward menjadi hal yang dikejar oleh para pemain sebagai representasi dari pencapaiannya di dalam gim. Namun begitu, sistem reward di dalam gim PUBG Mobile dibuat lebih kompleks agar pemain tidak mudah untuk mendapatkannya, dengan begitu akan muncul rasa penasaran yang membuat para pemain gim terus bertahan di dalam gim untuk terus berusaha mendapatkan reward sebanyak mungkin. Pada perkembangan selanjutnya, bersamaan dengan gim daring lainnya, PUBG Mobile merambah ke ranah ekonomi, di mana terjadi jual-beli akun dan juga bermunculannya streamer dan content creator yang menampilkan gim PUBG Mobile sebagai konten untuk menarik pemirsa dari seluruh penjuru dunia yang merupakan para pemain gim PUBG Mobile itu sendiri. Bermunculannya konten-konten ini juga turut berperan bagi terbentuknya trend sebagai bagian dari budaya populer yang menampilkan gim PUBG Mobile sebagai episentrumnya, tidak hanya sebagai bagian dari hiburan, namun juga sebagai gaya hidup, ajang pembuktian diri, ruang membangun relasi, kecerdasan, pemenuhan kebutuhan ekonomi dan lain sebagainya.

\section{Antara Individualitas Dan Kolektivitas}

Dalam ruang yang diisi oleh interaksi manusia, senantiasa terdapat ketegangan yang melingkupinya. Baxter (2004) mengistilahkan ini sebagai dialektika relasional, di mana selalu ada ketegangan-ketegangan yang berkelindan antara tindakan individu yang satu dengan individu yang lain atau justru antara individu dengan kelompoknya, seperti yin dan yang, berkontradiksi namun 
menciptakan keseimbangan di dalam ruang sosial itu sendiri. Pola ini juga terlihat dalam hubungan antara pemain gim PUBG Mobile, di mana keteganganketegangan itu direfleksikan melalui tindakan di antara individual maupun kolektif.

Penulis menemukan pola seperti ini terbangun dalam kompleksitas yang tidak dapat direkayasa oleh pengembang gim dengan alur yang diciptakannya sendiri, sebab kultur yang terbangun beserta perilaku para pemain di dalam gim tidak dapat diciptakan atau dimusnahkan. Pada prosesnya, bagaimana sebuah tindakan individual dan kolektif yang coba dibentuk oleh developer melalui fitur di dalam gim tidak serta-merta mengarahkan para pemain untuk patuh dan membentuk sebuah pola perilaku sesuai dengan bentukan para pengembang itu sendiri. Tentu saja ada keterbatasan-keterbatasan apabila orientasinya mengarah pada user based, namun dalam dinamika pasar, pengembang cenderung menuruti arah yang dikehendaki oleh para pemain yang dalam hal ini berperan sebagai konsumen.

Hal pertama yang terlihat dalam menjelaskan bagaimana tindakan individual dan kolektif terlibat dalam ketegangan antara pemain gim PUBG Mobile adalah reward oriented. Meski terbangun oleh keharusan untuk bekerja secara kolektif untuk mendapatkan reward maksimal sebagai hasil kerjasama kolektif tersebut, selalu ada kecenderungan pemain untuk secara individu mendapatkan reward maksimal, terlepas dari hasil kolektif yang dicapai secara kerjasama tim. Ketiadaan pembagian tugas dan peran di dalam alur permainan gim PUBG Mobile memunculkan indikasi bahwa dalam permainan kolektif tersebut, justru masingmasing pemain bermain secara individual dengan mengutamakan teknik-teknik dan skill individu, meski tidak dipungkiri jika semakin bermain kolektif maka peluang untuk menang semakin besar, namun individu-individu yang menonjol di dalam tim juga menjadi penentu utama.

Mekanisme reward yang mana pemain dalam tim dengan jumlah kill terbanyak yang mendapatkan reward lebih banyak dibanding yang lain juga berindikasi pada pemain-pemain yang unjuk kebolehan demi prestise dan juga reward yang nantinya ketika dikumpulkan dapat berguna bagi karakter pemain secara individual. Wang dan Sun (2011) melihat bahwa fenomena reward di dalam gim masih mengacu pada sistem yang digunakan di dalam gim di awal 
perkembangannya, para pengembang pada dasarnya belum menemukan cara untuk menarik konsumen selain dengan menggunakan reward. Reward senantiasa disimbolkan sebagai pencapaian individu, insentif yang diberikan kepada gamer atas kemampuan dan kecakapannya dalam bermain gim (Cruz dkk, 2017).

Selain reward oriented, sesama pemain juga terjebak dalam kompetisi internal untuk menjadi yang terbaik di antara rekan satu skuad. Dalam setiap permainan, selalu ada semacam perasaan bangga ketika pemain menjadi yang paling menonjol di antara yang lain (Greenberg, 1992; Fritz \& Bukiet, 2010; Kershnar \& Feit, 2001). Gim PUBG Mobile memiliki fitur yang menentukan pemain mana di antara empat anggota skuad yang pada akhir permainan dinobatkan sebagai pemain terbaik atau diistilahkan dengan MVP (Most valuable player), sebagai bentuk apresiasi sistem atas kinerja individual pemain di dalam tim, gelar MVP dalam gim PUBG Mobile secara langsung mendorong pemain, terutama dalam mode skuad acak (random) untuk tidak terlalu mementingkan apa yang dicapai secara kolektif, sehingga pemain cenderung melakukan tindakan beresiko dengan mencari kill meskipun harus terpisah dari rekan satu skuadnya.

Perasaan bangga adalah perasaan yang muncul secara individual, Aaker dan Willimas (1998) mengkategorikannya sebagai representasi ego individu, sebab walaupun sebuah pencapaian dihasilkan secara kolektif, tetap saja kebanggan adalah perspektif psikologis yang muncul secara individu. Sebagai contoh, seorang pemain sepakbola yang keluar sebagai pencetak gol terbanyak dalam suatu pertandingan memiliki dua kebanggan, pertama ia memenangkan pertandingan di dalam tim dan kedua ia mendapatkan panggung khusus karena kinerja individunya yang memenangkan tim tersebut, Majaro (2012) menyebut bahwa kebanggaan kolektif tidak terlalu berpengaruh dibanding kebanggaan secara individu, karena kesan yang muncul dalam kebanggaan kolektif tidak menempatkan diri siapapun sebagai yang terbaik, perspektif ini menyamakan kemampuan semua individu.

Selain reward oriented yang diselingi oleh kompetisi antar sesama pemain dalam satu anggota skuad untuk mendapatkan pengakuan (MVP) dari sistem, kebanggaan individu menjadi sesuatu yang paling menonjol di dalam hubungan antar pemain gim PUBG Mobile. Sebelum masuk ke permainan, masing-masing pemain secara tidak langsung menampilkan atau memamerkan skin-skin dan item- 
item yang berhasil didapatkannya di dalam gim. Semakin langka item-item yang bisa ditampilkan, maka akan semakin puas pula perasaan pemain tersebut, sebab kultur di dalam gim membentuk paradigma yang walaupun tidak dikonsensuskan, namun ia secara individu sudah bisa dikatakan hebat karena mendapatkan item-item tersebut.

Meskipun berada dalam suatu ruang yang tujuannya harus dicapai dengan tindakan kolektif, kecenderungan untuk bertindak individual sangat tinggi di dalam gim PUBG Mobile, di mana pemain tidak peduli dengan apa yang dicapai oleh teman bermainnya, sebab ia lebih fokus dengan apa yang hendak dicapainya secara individu. Selain itu, dinamika ini juga diiringi dengan konflik antar sesama anggota skuad, di mana jika sesama mereka tidak sinkron dalam bekerjasama di dalam permainan, cenderung lebih menyalahkan rekan setimnya, kadang-kadang antar sesama pemain saling memaki satu sama lain ketika ada yang berbuat kesalahan atau tanpa kesalahan sekalipun.

Dalam menentukan teman satu skuad pada mode squad non random, seorang pemain PUBG Mobile lebih mengutamakan kriteria yang menguntungkan dirinya secara individual, di mana ia harus memastikan bahwa teman satu skuadnya haruslah yang sudah memiliki rank yang tinggi, sehingga bisa menghindarkannya dari kekalahan awal yang berakibat pada berkurangnya rank yang telah dia capai. Ini menunjukkan orientasi yang cukup jelas bahwa dalam bermain seorang pemain gim PUBG Mobile lebih mengedepankan kepentingan individunya meski berjalan dalam proses kolektif, di mana ia bermain dan bekerjasama dengan kelompoknya.

\section{Kesimpulan}

Dalam sebuah ruang sosial di mana terdapat sebuah dinamika kolektif, selalu ada celah yang menunjukkan ketegangan antara individu dengan kelompoknya. Studi-studi terdahulu menekankan bahwa kelompok dengan segala yang berbentuk kolektif lah yang paling berperan, bahkan hingga pada menciptakan tindakan-tindakan individu yang ada di dalamnya, pandangan ini tidak sepenuhnya benar, sebab penulis menemukan bahwa kolektivitas yang terbangun di ranah virtual gim PUBG Mobile sesungguhnya berangkat dari individualitas itu sendiri, 
di mana kolektivitas mengambil peran seperlunya saja untuk mewujudkan tujuan individu-individu yang ada dalam ruang kolektif tersebut.

Ruang virtual yang kompleks dan egaliter tidak lantas mengarahkan pemain untuk melakukan tindakan yang setara dalam sebuah kerangka kerja yang kolektif. Ini menunjukkan bahwa upaya para pengembang gim daring dengan sistem yang diciptakannya untuk membawa para pemainnya keluar dari kekakuan yang individualistik belum sama sekali berhasil. Pada kenyataannya justru memanfaatkan sistem kolektif itu untuk menunjukkan sekaligus mengupayakan pencapaian individunya.

Penulis mengakui bahwa masih terdapat banyak kekurangan di dalam penelitian ini, karena itu penelitian yang lebih mendalam diperlukan untuk mengoreksi asumsi-asumsi dari penelitian ini. Penulis berharap, kedepan semakin banyak dilakukan penelitian sosial yang berfokus pada kultur yang terbangun di dalam gim daring, sehingga menjadi masukan bagi pengembang gim daring untuk mempertahankan konstruksi sosial yang normatif, bukan justru secara tidak langsung mengubahnya ke arah yang negative di dalam gim. 


\section{Daftar Pustaka}

Aaker, J. L., \& Williams, P. (1998). Empathy versus pride: The influence of emotional appeals across cultures. Journal of consumer research, 25(3), 241-261.

Bate, S. P. (1997). Whatever happened to organizational anthropology? A review of the field of organizational ethnography and anthropological studies. Human relations, 50(9), 1147-1175.

Baumeister, R. F. (1991). The meanings of life. New York: Guilford.

Baxter, L. A. (2004). A tale of two voices: Relational dialectics theory. Journal of Family Communication, 4(3-4), 181-192.

Bevir, M. (1996). The individual and society. Political Studies, 44(1), 102-114.

Boissevain, J. (1968). The place of non-groups in the social sciences. Man, 3(4), $542-556$

Chakrabarti, A. (1992). Individual and collective pride. American Philosophical Quarterly, 29(1), 35-43.

Cruz, C., Hanus, M. D., \& Fox, J. (2017). The need to achieve: Players' perceptions and uses of extrinsic meta-game reward systems for video game consoles. Computers in Human Behavior, 71, 516-524.

Franck, T. (2000). The empowered self: Law and society in the age of individualism.

Fritz, K., \& Bukiet, B. (2010). Objective Method for Determining the Most Valuable Player in Major League Baseball. International Journal of Performance Analysis in Sport, 10(2), 152-169.

Gerungan, W. A. (2004). Psikologi sosial. Bandung: Refika Aditama.

Gittell, R., \& Vidal, A. (1998). Community organizing: Building social capital as a development strategy. Sage publications.

Gluckman, M. (2017). Politics, law and ritual in tribal society. New York: Routledge.

Greenberg, K. E. (1992). Magic Johnson: Champion with a Cause. Minneapolis: Lerner Publications.

Hine, C. (2000). Virtual Ethnography. London: Sage Publications Ltd.

Hogg, M. A. (2008). Personality, individuality, and social identity. Personality and social behavior, 177-196.

Hussain, Z., \& Griffiths, M. D. (2009). The attitudes, feelings, and experiences of online gamers: a qualitative analysis. CyberPsychology \& Behavior, 12(6), 747-753.

Janis, I. L., \& Janis, I. L. (1982). Groupthink: Psychological studies of policy decisions and fiascoes (Vol. 349). Boston: Houghton Mifflin.

Jia, A. L., Shen, S., Bovenkamp, R. V. D., Iosup, A., Kuipers, F., \& Epema, D. H. (2015). Socializing by gaming: Revealing social relationships in multiplayer online games. ACM Transactions on Knowledge Discovery from Data (TKDD), 10(2), 11.

Jonasson, K., \& Thiborg, J. (2010). Electronic sport and its impact on future sport. Sport in society, 13(2), 287-299.

Kershnar, S., \& Feit, N. (2001). The most valuable player. Journal of the Philosophy of Sport, 28(2), 193-206.

Kesselring, T., \& Müller, U. (2011). The concept of egocentrism in the context of Piaget's theory. New Ideas in Psychology, 29(3), 327-345. 
King, A. (2009). Overcoming structure and agency: Talcott Parsons, Ludwig Wittgenstein and the theory of social action. Journal of Classical Sociology, 9(2), 260-288.

Kusumawardani, S. P. (2015). Game Online Sebagai Pola Perilaku (Studi Deskriptif Tentang Interaksi Sosial Gamers Clash Of Clans Pada Clan Indo Spirit). Jurnal Antropologi FISIP Universitas Airlangga, 4(2), 154-163.

Lee, D. (2000). The society of society: The grand finale of Niklas Luhmann. Sociological Theory, 18(2), 320-330.

Majaro-Majesty, H. O. (2012). Sports, emotional security, integration and peace: a cue from the non-participation of Nigerian national football teams at mundials. An occasional paper presented at the department of sociological studies, Tai Solarin University of Education, Nigeria.

Nassehi, A. (2002). Exclusion individuality or individualization by inclusion?. Soziale Systeme, 8(1), 124-135.

Nazir, M. (1988). Research methods. Jakarta: Ghalia Indonesia.

Newcomb, T. M. (1968). Interpersonal balance. Theories of cognitive consistency: A sourcebook, 28-51.

Postmes, T., \& Jetten, J. (Eds.). (2006). Individuality and the group: Advances in social identity. Sage.

Prayitno, E. (2006). Psikologi perkembangan remaja. Padang: Angkasa Raya.

Prentice, D. A. (2006). Acting like an individual versus feeling like an individual. Individuality and the group: Advances in social identity (p. 3755). Sage Publications, Inc.

Putnam, R. D. (2002). Bowling together. The American Prospect, 13(3), $20-22$.

Ramberg, B. T. (2014). Irony's Commitment: Rorty's Contingency, Irony, and Solidarity. The European Legacy, 19(2), 144-162.

Ritzer, G. (1990). The current status of sociological theory: The new syntheses. Frontiers of social theory: The new syntheses, 1-30.

Rudyansjah, T. (2015). Emile Durkheim: Pemikiran Utamanya dan Percabangannya ke Radcliffe-Brown, Fortes, Levi-Straus, Turner, dan Holbraad. Jakarta: Kompas.

Sapach, S. C. (2015). The WoW Factor: A Virtual Ethnographic Study of Sacred Things and Rituals in World of Warcraft. In Radde-Antweiler, K. Methods for Analyzing Let's Plays: Context Analysis for Gaming Videos on YouTube. (p. 40-100) gamevironments, (2).

Sarwono, W. Sarlito, dan Meinarno, A, Eko. (2009). Psikologi Sosial. Jakarta: Salemba Humanika.

Sayers, S. (2007). Individual and society in Marx and Hegel: Beyond the communitarian critique of liberalism. Science \& Society, 71(1), 84-102.

Tajfel, H. E. (1978). Differentiation between social groups: Studies in the social psychology of intergroup relations. Academic Press.

Turner, J. C. (1999). Some current issues in research on social identity and selfcategorization theories. Social identity: Context, commitment, content, 3(1), 6-34.

Turner, J. C., Oakes, P. J., Haslam, S. A., \& McGarty, C. (1994). Self and collective: Cognition and social context. Personality and social psychology bulletin, 20(5), 454-463. 
Turner, J. C., Reynolds, K. J., Haslam, S. A., \& Veenstra, K. E. (2006). Reconceptualizing personality: Producing individuality by defining the personal self. In T. Postmes \& J. Jetten (Eds.), Individuality and the group: Advances in social identity (p. 11-36). Sage Publications, Inc.

Walgito, B. (2007). Psikologi kelompok. Yogyakarta: Andi.

Wang, H., \& Sun, C. T. (2011). Game reward systems: Gaming experiences and social meanings. In DiGRA Conference (Vol. 114). 